\title{
On Establishment of Computer Science and Technology Course System
}

\author{
Wu Li-hua \\ NanChang Institute of Science \& Technology
}

\begin{abstract}
In today's science and technology, the computer is one of the most important and key. The gradual development of computer technology and extensive application of computer science and technology to gradually transform into an independent professional discipline, therefore, the scientific construction of its professional curriculum system is also particularly important. On the basis of the full consideration of the characteristics and the main areas of computer science, this paper puts forward the idea of designing the course of "Introduction to computer" by computer science and technology.
\end{abstract}

Keywords-Computer Science and Technology; Content Construction; Teaching Status

\section{INTRODUCTION}

With the development of computer industry in China, the demand for computer professionals is increasing rapidly, and the computer specialty is not only in the University and college, but also in the secondary vocational schools. This, of course, is to some extent alleviate the plight of the lack of computer talent, but also a series of problems. Different colleges and universities have different levels of computer professional training, and the actual level of students is also very different. This has led to a lot of computer personnel, on the other hand, the market demand for the computer class talent gap is very big. The reason is that it can be adapted to the shortage of talents, such as computer personnel training in Vocational Education Center is in the high, low, not on the awkward situation, employment has become a prominent problem restricting the development of Vocational education.

Today's society has entered the era of information, the computer has become one of the most popular professional, with the rapid development of China's economic construction, the IT industry has been rapid development, and IT talent has become the major companies competing to take the object, of course, we are here to say, is a high-quality, highly skilled personnel. Throughout the present computer talent market, talent and a lot of, but can really meet the requirements of the market, but not much. University is the source of computer personnel, most of the talent is through the training of the university system, and the debut, now the quality of the computer talent on the market cannot meet the requirements, a large part of the reason is that the current college computer professional teaching is not perfect.

Starting from the present situation of students' employment, this paper analyzes a series of problems occurred in the course of computer specialty curriculum reform.

\section{PROBLEMS IN THE CURRICULUM SYSTEM OF COMPUTER SCIENCE AND TECHNOLOGY}

Too much focus on core discipline. Most of today's colleges and universities in the computer science and technology professional or even all professional courses, often set up a core discipline as an important part, and then as a point, to set up the rest of the course. But the development of most courses is closely linked with the development of social economy, the requirements of the course should also meet the needs of social development. But too much focus on the core discipline will cause the students to learn and thinking is restricted, cannot keep up with the development of society. Therefore, the computer science and technology professional curriculum should continue to update, with the times.

\section{DEFINITION AND FUNCTIONS OF COMPUTER SCIENCE AND TECHNOLOGY METHODOLOGY}

Computer science and technology methodology is a systematic study of the general method and its nature, characteristics, internal relations and development of the 
process of understanding and practice in the field of computer science. Computer scientists have made a lot of scientific achievements in the past 50 years, so that the discipline has been developed rapidly. At the same time, these scientists have created a lot of tools to obtain these results. The task of computer science and technology is to sum up and improve these methods systematically, so that it becomes a universal tool, so that we can better engage in the work of the field.

From the development of computer science, it is closely related to the improvement of research methods, and the development of computer science and the development of the research method of the research method in the period of time. For example, in 1950s, the program design was subject to the limitations of the technology, the design of the program using techniques that is, a certain method; Due to the software crisis and the development of hardware in the late 1960s, there have been a standardized programming design; At the end of 1970s, a structured system development method was formed; In 1980s, it was found that because of the barriers to the language of the industry, it is difficult to find out the needs of the user; In 1990s, with the further deepening of people's understanding, to face the real world to solve the real world, put forward the dominant object-oriented thinking method.

\section{ESTABLISHMENT OF COMPUTER SCIENCE AND TeChNOLOGy COURSE SYSTEM}

1, Make clear positioning, formulate scientific training mode. For the cultivation of computer science and technology professionals should focus on the cultivation of practical ability and the overall quality of the development of a professional scientific training objectives. Specifically: With a solid foundation, wide knowledge, strong practical ability, master computer science and technology basic theory, basic knowledge and basic skills, in the computer science and technology and its application in the field of computer teaching, scientific research, scientific and Technological Development and management of senior professionals. Can be the students for computer science and technology of the course study and time is divided into two parts: the curriculum of basic knowledge in the teaching of the first two years, the remaining two years of study for diversion.
2, Actively improve and improve the teaching content. In the construction of computer science and technology curriculum system, we should set the teaching objectives as the basis, from the whole market background. For the computer science and technology courses, can be divided into teacher education courses, basic courses and professional courses (will / elective), professional elective course is mainly the computer's popular technology or emerging technology, can also be said to be very practical computer technology, to expand students' knowledge. According to the characteristics of the students, the selection of a part as the focus of its training, targeted for students to develop, so that both academic and application of talent can be a good training and development.

\section{V.CONCLUSION}

At present, the University Computer Science and technology teaching situation is not optimistic, as teachers, we need to continue to explore and research, the use of a variety of effective teaching methods, continuous reform and development of teaching mode, to further promote the development of computer science and technology education. Computer science and technology, which covers a very wide range of knowledge, is bound to involve those scientists who have made great contributions to the history of computer science. In this paper, the design may also have a shortage of hope in the future use of continuous improvement, make the system more stable, for the future teaching work to provide convenient, enhance the teaching effect, make due contribution to the development of the society.

\section{REFERENCES}

[1] Petkov, V., and M. Mikhov. "Magnetic phase diagram of the MnAs spin system. A computer simulation." Journal of Physics C Solid State Physics 18.19(1985):3791-3795

[2] Hennessy J L, Patterson D A. Computer Architecture - A Quantitative Approach[J]. Computer Architecture A Quantitative Approach, 2007.

[3] Kalinowski S T, Taper M L, Marshall T C. Revising how the computer program cervusa ccommo dates genotyping error increases success in paternity assignment[J]. Molecular Ecology, 2007, 16(5):1099-1106(8).

[4] Hartley R, Zisserman A. Multiple view geometry in computer vision[J]. Cambridge University Press, 2003, 30(9-10):1865 1872.

[5] Sarrafzadeh M. Department Of Electrical Engineering And Computer Science[J]. Journal of Chemical Education, 2001, 3(6):II - 1001-4.

[6] Bernstein FC; Koetzle TF; Williams GJ; Meyer EF Jr; Brice MD; Rodgers JR; Kennard O; Shimanouchi T; Tasumi M. The protein data bank: A computer-based archival file for macromolecular 
structures[J]. Archives of Biochemistry \& Biophysics, 1978, 185(2):584-591.

[7] Petkov, V., and M. Mikhov. "Magnetic phase diagram of the MnAs spin system. A computer simulation." Journal of Physics C Solid State Physics 18.19(1985):3791-3795.

[8] Kalinowski, STEVEN T., M. L. Taper, and T. C. Marshall. "Revising how the computer programcer vusac commodates genotyping error increases success in paternity assignment." Molecular Ecology 16.5(2007):1099-1106(8).

[9] Berk R A, Schoenberg F. Workshop on statistical approaches for the evaluation of complex computer models[J]. Statistical Science, 2002:173-192.
[10] Bernstein FC; Koetzle TF; Williams GJ; Meyer EF Jr; Brice MD; Rodgers JR; Kennard O; Shimanouchi T; Tasumi M. (1978). The protein data bank: a computer-based archival file for macromolecular structures. Archives of Biochemistry \& Biophysics, 185(2), 584-591.

[11] Saltzer, J. H., and Schroeder, M.D. "The protection of information in computer systems." Proceedings of the IEEE 63.9(1975):1278-1308

[12] Farin G, Farin G. Curves and surfaces for computer aided geometric design - a practical guide (3. ed.).[J]. Academic Press Inc Boston Ma, 1993. 